\title{
O corpo entre o rádio e a comunicação oral: estudos contemporâneos
}

\section{Wilton Garcia}

\section{Resumo:}

Esta proposta de escrita instaura-se como ensaio de ideias, cujo escopo aborda o corpo diante da relação rádio e comunicação oral, em um viés interdisciplinar. Busca-se evitar posições isoladas, ao convocar categorias discursivas como imagem, tecnologia, corpo e subjetividade. Estrategicamente, trata-se de alargar os processos concepto-teórico-metodológicos, a fim de não acomodar os fatos em uma zona de conforto. Mais que isso, articular a produção de conhecimento acerca de múltiplos referenciais, no âmbito da linguagem: ou seja, a estratificação entre cultura e representação, instauradas pelos estudos contemporâneos

\section{Palavras Chave:}

Corpo, rádio, comunicação oral, interdisciplinaridade, contemporâneo.

\begin{abstract}
:
This article is written as an inter-disciplinary essay to discuss the body in relation to radio and oral communication. Avoiding isolate positions, we invoke discursive categories such as image, technology, body and subjectivity. Strategically, we aim to stretch concepts, theories and methodological processes, in order not to accommodate facts in a comfort zone. More than this, we articulate knowledge production considering a diversity of references in language: the stratification between culture and representation, as set by contemporary studies.
\end{abstract}

\section{Keywords:}

Body, radio, oral communication, interdisciplinarity, contemporary.

Como professor e pesquisador resolvi soltar a voz! Conforme se utiliza a vibração da voz, se ganha força. Vamos celebrar o rádio. Como uma marcha rítmica, caminhar para frente ao eleger a dinâmica oral para este feito. Embora não precise ser reto, apenas correto. Nada de berro, porque não é gritar. Basta apenas ser ouvido pela plateia, sem escândalo ou perturbação.

E não poderia ser um breve monólogo, mas sim um diálogo constante. Um ato relacional. Parcialmente, é possível dizer, encantar: cantar uma canção; recitar um poema; interpretar um personagem; estudar a extensão do som. Enfim, fazer o pensamento tomar vida própria em sua (re)inscrição. 
Antes, porém, anuncio que é a partir do corpo que penso o rádio e a comunicação oral. Tenho investigado a noção de corpo contemporâneo, ao apontar impressões que se estendem em transcorporalidades (GARCIA, 2005); isto é, o trânsito do corpo, não o tráfego. Entre gestos e expressões faciais, postura e vestimenta, a aparência indica informação suficiente para comunicar.

Para fomentar intercâmbios de pesquisas interdisciplinares (FAZENDA, 2008) na produção de conhecimento, este estudo promove um fluxo contingencial de expressões díspares e complementares, que acoplam conceito e crítica. Entretanto, intercambiar, aqui, é muito mais que trocar experiências e informações, pois isso garantiria o mero deslocamento sistêmico, fazendo com que cada eixo pudesse expor resultados híbridos (CANCLINI, 2008). Então, vamos agitar o percurso!

Isso só é possível com a proposta de um pensar atual capaz de articular aberturas necessárias para essas trocas, (re)configurações e/ou intercâmbios feitos em (com)partilhamento de ideias e soluções criativas. Os intercâmbios servem para ampliar oportunidades e promovem fluxos de informações, que transitam em diferentes segmentos acadêmicos ou mercadológicos.

Em tempos de ações colaborativas, compartilhamentos de saberes, trocas de experiências, intercâmbios de ideias, interatividades e redes de conexões, diferentes posicionamentos dos campos de saberes emergem atrelados às diversas formações estéticas, comunicacionais, científicas e filosóficas. A comunicação e a produção do conhecimento, nesse instante, reverberam em articulações intermediadas pela representação e pela cultura; ou seja, na efervescência da linguagem.

A voz carrega o discurso: um legítimo exercício de codificação e decodificação de idéias (re)organiza a condição adaptativa da existência humana. A comunicação, então, deve ser absorvida pelo código radiofônico. São mediações sonoras: um tilintar de sinos, um apito de fábrica, um rádio-repórter, uma freada de carro.

Falo do tecido coeso que alinha fios e linhas em uma vertente complexa - trama de (re)significações. Um paradoxo: transito da ideia ao texto em uma tentativa desesperada de equilíbrio como resultante provisória, a qual demarca a expressão - em manifesto. Eis o escopo de expor um textopromessa.

Quem nunca pensou em algo, mas que naquele precioso momento não foi possível dizer? Por isso, vamos abrir a boca. Gesticular, afirmar, posicionar-se. Porque aqui será permitido dizer. Nada de proibições.

A comunicação oral se faz pelo desempenho radiofônico que entoa vozes entre emissor e receptor em uma profunda comunhão com o Outro. A fala interativa materializa um pensamento, uma tentativa de controle vetoriza do interno ao externo (do intrínseco ao extrínseco; de dentro para fora) e vice-versa.

A sociedade contemporânea redireciona o interesse da ideologia para a tecnologia. Evidente que continuam os fins ideológicos ao expor movimentos políticos; embora a força da cultura digital seja muito mais intensa diante do consumo.

$\mathrm{Na}$ expectativa de um conviver, é reconhecer a diferença que explora as alternativas, a diversidade. Meu pensamento pode ser diferente do seu. E, neste ato, não cabem julgamentos. Portanto, ele não é pior, nem melhor. Seria apenas um outro posicionamento, exposto por mercado e mídia.

Dessa forma, a comunicação oral que avisto trata de compartilhar, desmembrar, somar e ajustar os ideais. Nada de pontuar um sistema fechado ou estanque. A proliferação dos enunciados discursivos só pode agregar as novidades e as inovações.

É a ação de perceber o mundo e tentar atualizar os objetos em seus respectivos contextos e representações. As coisas acontecem e é necessário acompanhar o futuro das ideias. Isso seria atualizar. O avançar como quem não acomoda o pensamento numa mesmice.

\section{Tecnologias}

O que mais amplia esse mundo de possibilidades? A cultura digital põe em cheque a ideia de mediação. $\mathrm{O}$ impacto das tecnologias emergentes remete aos percursos contingenciais, diferenciadores de tempo-espaço, os quais também acoplam e desdobram forma e conteúdo. $\mathrm{O}$ digital faz surgir novos enlaces perceptivos, cognitivos e as tecnologias (retro)alimentam a noção de corpo. 
Falo de um corpo que absorve as (trans/de)formações e se compõe diante da linguagem. Tais modificações somam as metamorfoses do corpo junto aos aparatos maquínicos (VILLAÇA, 2007). Isso ocorre diante das implementações que (re)absorvem novas vertentes tecnológicas, as quais instigam pensar a estratificação do corpo atual. Os dispositivos interferem na máquina, na ação e no corpo. Por isso, a repetição reitera, ressignifica. Já ouvi esse som. Então, saiba que ao assistir novamente você pode descobrir algo novo para si.

Assim, penso no processo de interação em que a comunicação oral, em particular, passa a ser mediada pelo computador e seus aportes, provocando mudanças nos modos de representação. Afinal, estamos falando de um plano real, virtual ou atual, como quer Pierre Lévy (1998). A máxima da criação, sobretudo com a tecnologia digital, está na expectativa de propiciar estrategicamente um diferencial criativo. Algo que expande, amplia e dá um "novo/outro" contexto. Uma atmosfera subjetiva.

Entre benefícios e malefícios, a façanha das tecnologias, agora, está abarcada pelo (des)envolvimento do mercado, da mídia e do pensamento contemporâneo. Mídia e mercado procuram a(di)cionar novos territórios, o que ativa o consumo, vende produtos, incute idéias.

E, nesse caso, para atualizar a informação, o futuro digital reconfigura imagens, sons e textos, cujos aparatos instrumentais e ferramentais não conseguem equacionar a própria produção do conhecimento.

\section{Com corpo}

Um tecimento (in)orgânico dilata a noção de corpo à projeção de variantes discursivas que (re)configuram o contemporâneo. Há uma parceria de desdobramentos hipermidiácos recorrentes na educação, como predicações retóricas para atender à formação do sujeito. A (inter)mediação estratégica entre corpo, educação e tecnologia - equaciona um sistemática pontual com diferentes proposições, os quais (re)versam uma produção de conhecimento.

Experiências corporais, por exemplo, são acionadores percepto-cognitivos que favorecem a (inter)mediação do processo criativo e do conjunto bio-psico-social em consonância adaptativa com cada contexto. Do ponto de vista da linguagem, verifica-se a relação objeto e contexto quando se promulgam as instâncias representacionais. De modo estratégico, a interligação corpo e ambiente constitui aspectos relevantes às diretrizes, que enfocam temas relacionados aos valores humanos na constituição e formação do sujeito.

A atmosfera de corpos dissipa a própria contingência da cultura dos objetos tecnológicos. E, diante disso, notam-se os meios de comunicação em sua plena efervescência acelerada. Entre gestos e expressões faciais, postura e vestimenta, a aparência indica informação suficiente para comunicar.

Hoje, o corpo acaba exigindo uma (re)articulação crítica e criativa para se pensar uma arena interdisciplinar das ciências humanas, entre arte, comunicação, design e moda, sobretudo a publicidade. Logo, o corpo emerge como tema recorrente de desafios e debates conceituais atuais, pois ele é portador (material e, ao mesmo tempo, subjetivo) da diversidade.

\section{Sem imagem}

E saiba que: hoje não tem imagem! Imagine tentar prender a imagem, porque o que vale é a comunicação oral: nada de fotografia, desenho, pintura, gravura, cinema, TV, infografia ou qualquer outro código imagético? Pois hoje é sem imagem. Música pode. Funk, samba, pagode, bolero, tango, rock, hip-hop, xaxado, punk, forró, macumba, jazz, valsa, sertanejo, mpb. A diversidade impera e espalha o tom.

Apenas foi lançado o espaço da palavra radiofônica - sem alternativas. Não há linguagem sincrética, nem hibridismos ou misturas expressas em uma lógica formal da escritura. Grau zero para a imagem - reprovação. De acordo com a tecnologia, forma e conteúdo podem ser (re)editados, porque hoje não há vestígios. Fechem os olhos, uma vez que não será permitido ver. Somente a ordem do verbo (ou melhor, do som) pode ajudar na constituição da representação. A obediência à comunicação oral deve reinar. 
O que é dito, então, vale mais que o escrito, assinado ou o testemunhado. Seria o limite? A fronteira? É tentar apagar a sensação de dependência sincrética, pois se pretende re-traduzir - reconduzir o código semiótico. As combinatórias almejam o eco. Reitera-se na repetição.

Agora, decretou-se que não haveria nenhum outro modo de dissipar a mensagem, senão a comunicação oral para a respeitosa audiência. Ironia, talvez! É refletir sobre o meio, o suporte e a recepção. Tudo muito estrondoso ergue a perspectiva instaurada: hoje não tem nada além do sopro sonoro, como o barulho do toque de tambor. A dança acontece na cadência marcante da balada que embala; porque balançar o corpo é ritmar as energias.

E se, por acaso, alguém pedir flores, elas precisam ser descritas pela escala sonora: na pecularidade de quem sente, remexe, descreve e anota a simbiótica simbologia do termo. A vicissitude equaciona-se numa fluidez de (re)pensar sua estrutura genética de planta, equiparada entre o caule, as pétalas, a cor e, até mesmo, o cheiro. Porque hoje só o som tem graça.

\section{Informação}

A forma de composição da informação no contemporâneo é bastante variada - vide a fofoca ou o telefone sem fio. As variantes de leituras e criação (de imagens, experiências, representações e subjetividades) são condições adaptativas fundamentais para o processo de ensino-aprendizagem, por exemplo, na educação e no mercado profissional.

Parto dessa premissa para dizer que a informação, hoje, é fragmentada, não-linear e simultânea. Ela ocorre a partir de entrecruzamentos de manifestações que tornam complexas a experiência contemporânea. Contemporâneo, que aqui deve ser visto/lido para além do aspecto temporal, cronológico que determina o agora. O tempo presente.

Para Homi Bhabha (1998), o contemporâneo é parcial, provisório, efêmero, inacabado; ou seja, algo que desloca, desliza, amplia e não se fixa. Trata-se de uma projeção conceitual capaz de relacionar a subjetividade do contemporâneo como espaço aberto - em constante transformação.

Com efeito, comunicar é uma incerteza e requer mais que emissor, receptor, mensagem, código e canal. Reagrupa-se entre a disposição da interatividade. Um procedimento comunicacional suscita resultados. Por exemplo: da cobertura radiofônica ao locutor, prevalece a notícia, o jingle ou, até mesmo, o discurso efetivo na transmissão de uma rádio-atividade. Nisso, falador e ouvidor são inseparáveis.

Logo, o usuário-interator preenche a compreensão de uso e função das coisas que se transformam em produtos tecnológicos numa proposição coerente de desafios. Ao pensar a informação contemporânea dessa maneira, evidenciam-se as tecnologias emergentes.

\section{Em verbo}

No princípio, era apenas o verbo! Um ruído, um psiu, uma tosse, um gruído ou era apenas um respirar profundo que ventila o som do peito. Num turbilhão de orações, frases e sentenças organizam-se idéias, mensagens, códigos, lembranças e memórias. Entretanto (emprestado do design), mídia e mercado procurem o princípio da síntese: expressar o máximo no mínimo.

O que fazer diante dessas condições? A experiência radiofônica perpetua a possibilidade diversificada entre descrever, analisar e interpretar. São leituras distintas, porém com níveis complementares entre o transmitido e o recebido. Por isso, a disposição dos argumentos de um (inter)texto sonoro, uma conversa ou uma entrevista potencializam-se mediante o verbo que se verbaliza; e a banda som se ouve, recorrente do esforço de manifestar qualquer pensamento: expressão (re)codificada e materializada pela oralidade.

A passagem da imaginação à tessitura refinada da voz convoca uma dinâmica aflita com a fala anunciada a partir de entranhas: garganta, língua, boca. Nada pode conter a excelência do verbo em si! A lógica rítmica do texto poético ou em prosa evoca e estimula a (re)significação de resultados, numa tradução inter-semiótica. A partir da palavra e sua cantata ressalta-se a cena, cujo destaque legitima traços emblemáticos de voz, gesto, escrita, som e imagem.

Busquei na mata virgem o tom enigmático de Guimarães, mas me perdi entre as pedras no 
caminho de Drummond. Talvez pudesse ser a trilha que mostra o Rio forte de João Cabral ou a praia cabocla de Caymmi. Quem sabe, até mesmo, o retrato de uma família falida ou, ainda, a fazenda São Bernardo com o feito grotesco do coronel. Do sonho de Helena ao devaneio de Lara, o desejo se rebate em cenas indescritíveis. Com o sabor brasileiro "aportuguesado" dos lábios de mel.

Paradoxalmente, o inefável urge, aparece. Assim, tudo pode acontecer quando as articulações do vocábulo tomam forma sonora. Parece que alguém contou um conto. Alguém pontuou um ponto.

\section{O interdisciplinar}

Diante de tamanha atividade, elegem-se reflexões de olhares contemporâneos acerca do interdisciplinar. Neste instante, quero discorrer, um pouco, sobre a confluência do interdisciplinar (FAZENDA, 2008).

Hoje, a noção de disciplina está falida; e Foucault já o anunciou. Isso não é uma crítica; seria meramente uma constatação, sem julgamento de valor. Sobretudo com os avanços tecnológicos, não seria mais possível pensar apenas qualquer temática pelo viés específico desta ou daquela disciplina.

Para além de uma visão unilateral, expõem-se traços enunciativos que aproximam e, simultaneamente, distanciam dinâmicas do interdisciplinar em variedades multi-trans-pluri-disciplinares. É mesclar e viabilizar a versatilidade que paira sobre a comunicação - ainda mais com a flexibilidade do rádio.

O pensamento, portanto, se reconduz estrategicamente por alternativas, princípios e interstícios. São polifonias expostas em lacunas, gaps, entre-lugares. Arestas que somam o sistema. Aqui ninguém é contra o sistema, pois é necessário operar no sistema para se contaminar dele e, por esforço crítico, contaminá-lo.

O cotidiano, agora, suscita novas inquietações para (re)ver/(re)ler o debate acerca desse estado latente, pulsante, do interdisciplinar. $\mathrm{Na}$ esfera das regularidades, o que vale são as várias áreas do conhecimento humano debruçadas sobre o mesmo tema. Antropologia, arquitetura, artes, biologia, cinema, comunicação, design, educação, filosofia, geografia, medicina, psicologia e tecnologia, por exemplo, investigam o corpo contemporâneo.

Trata-se de estimular um (des)envolvimento sobre o leque da pesquisa que se abre, a fim de constituir novos modos de refletir sobre o trabalho investigativo. Muito já se falou acerca desse tema; no entanto, cabe (re)instaurar um movimento de atualização para reiterar as inovações crítico-conceituais e teórico-metodológicas que constituem os entrecruzamentos - as transversalidades - da/na ciência hoje.

\section{Sagacidade}

Consideremos o enredo de um filme ou o roteiro de uma boa história. À exemplificação de uma alegoria, um mito. Em Ulisses (escrito entre 1914-1921), Homero apresenta o caminho para Ítaca em uma saga(cidade) de ataques e defesas, que dura vários anos. A obra descreve um enorme valor literário por ressaltar aspectos da fisiologia humana.

Herói grego, Ulisses quando jovem interessou-se por Helena, porém casou-se com Penélope. Dessa união nasceu um filho (Telêmaco), do qual teve de se separar muito cedo para lutar ao lado de outros nobres gregos em Tróia. Por prudência, astúcia e bravura, foi atuante no cerco de Tróia e se destacou.

Ele, guerreiro valente quer retornar ao seu reino, Ítaca, uma bela ilha grega. No entanto, depara-se com a fúria de Posídon (com ondas gigantes), como náufrago à deriva. Entre os rochedos falantes, além do encanto mágico e sereno das sereias, Ulisses tenta conduzir o barco para alcançar sua morada.

Uma passagem significativa nessa história é quando ele tem que atravessar o oceano sem ser seduzido pelo som profundo das sereias. Para conseguir avançar rumo a Ítaca e não ser atingido pelo canto doce feminino, ele se prende com cordas no mastro do navio. Fica amarrado para não sair correndo e se atirar aos braços encantados. Afinal, é uma ilusão sonora, como uma miragem (uma mira de imagemsom)! Também, encoberta o ouvido com cera por não suportar esse deleite da voz suave, que clama pelo prazer, que chama para o mar. 
À sua espera está Penélope, jovem cobiçada por todos, com uma fidelidade obstinada, apesar da demora dos dez anos de viagem. Com a ajuda de Zeus e de outros deuses, Ulisses chegou em casa sozinho para encontrar sua esposa Penélope. Disfarçado como mendigo, primeiro verificou se ela era fiel e, em seguida, matou os pretendentes à sua sucessão, que a perseguiam, limpando o palácio. Com isso, iniciou-se uma batalha final contra as famílias dos homens mortos, mas a paz foi restaurada por Atena.

\section{Com som}

Hoje tem som no rádio. Muito mais que o silêncio!

É preciso deixar que a sonoridade se acenda como o fino limite das gotas das folhas que caem das plantas. Será a fresca do orvalho? Talvez o barulho das ondas do mar possa romper mais que um tônus impactante.

Porque deve haver algum tipo de sonoridade que abasteça os ouvidos. Isso também será ouvido. Ligue o telefone celular e deixe a porta do carro bater forte, para projetar qualquer coisa estridente. Uma batucada mesmo!

E, quando alguém solicitar que a música continue, diga que agora pode muito mais que o silêncio. O vento soprará com violência ou a chuva cairá com força, pois podem bater na copa das árvores e provocar alvoroço. Um anúncio levantará a voz bacana e a locução do rádio postará qualquer mensagem em compasso rítmico.

Há muita música, discurso, falatório e poluição sonora. Todo mundo grita, a porta emite ruído, a buzina toca, o galo anuncia, a mãe de santo reza, o maestro rege, a intérprete canta, o trem apita. Enfim, a vida se reinicia. Sem crise.

\section{Bibliografia:}

BHABHA, Homi K. O local da cultura. Belo Horizonte: Editora UFMG, 1998.

CANCLINI, Néstor Garcia. Leitores, espectadores e internautas. São Paulo: Iluminuras, 2008.

FAZENDA, Ivani C. Arantes. Interdisciplinaridade: história, teoria e pesquisa. $15^{\mathrm{a}}$ ed. Campinas: Papirus, 2008.

GARCIA, Wilton (org.). Corpo \& interatividade: estudos contemporâneos. São Paulo: Factash, 2008. . Corpo, mídia e representação: estudos contemporâneos. São Paulo: Thomson Learning, 2005.

LÉVY, Pierre. A inteligência coletiva: por uma antropologia do ciberespaço. São Paulo: Loyola, 1998.

MEDITSCH, Eduardo (org.). Teorias do rádio. Florianópolis: Insular, 2005.

NOVAES, Adauto (org.). Mutações - ensaios sobre novas configurações no mundo. Rio de Janeiro: Agir; São Paulo: Sesc SP, 2008.

VILLAÇA, Nizia. Edições do corpo: tecnociência, artes e moda. São Paulo: Estação das Letras, 2007.

\section{Mini Currículo :}

Doutor em comunicação e estética do audiovisual pela ECA-USP, com pós-doutorado em multimeios pelo IA-UNICAMP. Atualmente, é professor do Mestrado em Semiótica, Tecnologias da Informação e Educação da Universidade Braz Cubas (UBC). Autor de Corpo, mídia e representação: estudos contemporâneos (Thompson, 2005), entre outros. 